4. Paterick TE, Umland MM, Jan MF, Ammar KA, Kramer C, Khandheria BK, et al. Left ventricular noncompaction: a 25-year odyssey. J Am Soc Echocardiogr. 2012; 25:363-75.
5. Postma AV, van Engelen K, van de Meerakker J, Rahman T, Probst S, Baars MJ, et al. Mutations in the sarcomere gene MYH7 in Ebstein anomaly. Circ Cardiovasc Genet. 2011;4:43-50.

\title{
Right ventricular failure from severe pulmonary hypertension after surgery for shone complex: Back to fetal physiology with reducting, atrioseptectomy, and bilateral pulmonary arterial banding
}

\author{
Heiner Latus, MD, Can Yerebakan, MD, Dietmar Schranz, MD, and Hakan Akintuerk, MD, Giessen, \\ Germany
}

Deciding whether to create a univentricular or biventricular circulation in patients with borderline left ventricular (LV) structures in the neonatal period is challenging. We describe a case in which we used a unique approach intended to imitate cardiac physiology in a "fetal parallel circulation." We call this procedure in neonates with borderline LV the "Giessen hybrid approach." 1

\section{CLINICAL SUMMARY}

A 15-month-old male patient was referred to our center for evaluation of a potential cardiac transplant. Initial diagnostic evaluation and subsequent surgical treatment with neonatal repair of a coarctation of the aorta had been performed in another center for Shone complex, including mitral valve stenosis, LV outflow tract obstruction, stenotic bicuspid aortic valve, and a hypoplastic aortic arch with severe aortic coarctation. Because of multiple life-threatening pulmonary hypertensive crises with right heart failure, the patient underwent reoperation at the age of 9 months. Reoperation included reconstruction of the stenotic aortic valve and relief of the LV outflow tract obstruction, followed by extracorporeal membrane oxygenation treatment and early reoperation for severe mitral regurgitation. Despite specific medical therapy with sildenafil citrate (INN sildenafil), the patient was still affected by $\mathrm{PH}$ with a severe precapillary component,

From the Pediatric Heart Center Giessen, Justus-Liebig University, Giessen, Germany.

Disclosures: Authors have nothing to disclose with regard to commercial support. H.L. and C.Y. contributed equally to the article.

Received for publication April 25, 2014; revisions received June 16, 2014; accepted for publication July 7, 2014; available ahead of print Aug 28, 2014.

Address for reprints: Dietmar Schranz, MD, Pediatric Heart Center, Justus-LiebigUniversity of Giessen, Feulgenstrasse 12, D-35392 Giessen, Germany (E-mail:

dietmar.schranz@paediat.med.uni-giessen.de).

J Thorac Cardiovasc Surg 2014;148:e226-8

$0022-5223 / \$ 36.00$

Copyright (C) 2014 by The American Association for Thoracic Surgery

http://dx.doi.org/10.1016/j.jtcvs.2014.07.042 resulting in suprasystemic pulmonary arterial pressure of $89 / 52 / 67 \mathrm{~mm} \mathrm{Hg}$ and systemic arterial pressure of 69/ $37 / 50 \mathrm{~mm} \mathrm{Hg}$ (pulmonary capillary wedge pressure of $15 \mathrm{~mm} \mathrm{Hg}$ ) and leading to recurrent $\mathrm{PH}$ crises and episodes of cardiopulmonary resuscitation.

At the patient's presentation in our center, echocardiography showed a hypertrophied right ventricle (RV) and a secondary tricuspid regurgitation with a systolic gradient of $100 \mathrm{~mm} \mathrm{Hg}$ (tricuspid valve annulus of $20 \mathrm{~mm}$; $z$ score of 0.7). The LV was small (LV internal dimension in diastole of $22 \mathrm{~mm}$; $z$ score of -2 ), and the mean diastolic gradient across the only minimal regurgitant mitral valve (annulus of $10 \mathrm{~mm} ; z$ score of -3 ) was $8 \mathrm{~mm} \mathrm{Hg}$ (maximal value of $16 \mathrm{~mm} \mathrm{Hg}$ ). The echogenic interventricular septum deviated to the left, the LV outflow tract was narrowed to $5 \mathrm{~mm}$, and the dysplastic and bicuspid aortic valve (annulus of $6 \mathrm{~mm} ; z$ score of -5 ) still had a maximal gradient of $60 \mathrm{~mm} \mathrm{Hg}$.

In light of the patient's medical history with multiple lifethreatening events, the abnormal morphology of the LV with endocardial fibroelastosis (Figure 1), and the large difference in the diameter of the pulmonary and aortic annulus (12 $\mathrm{mm}$ vs $6 \mathrm{~mm}$ ), we decided against a Ross-Konno operation and cardiac transplant and instead opted for a palliative strategy. On the basis of our experience in neonates with a borderline $\mathrm{LV},{ }^{1}$ an 8 -mm polytetrafluoroethylene prosthesis was positioned between the main pulmonary artery and the distal aortic arch, thereby creating a "new arterial duct." The operation was performed through a median sternotomy with cardiopulmonary bypass at $30^{\circ} \mathrm{C}$. This strategy of a "reverse" aortopulmonary shunt was combined with atrial septectomy and bilateral pulmonary arterial banding (bPAB) with a 5-mm polytetrafluoroethylene graft. The patient could be discharged home on postoperative day 21 under medical treatment with bosentan and sildenafil.

After an uneventful period of 4 months without any PH crises, the patient was seen in improved clinical condition, 

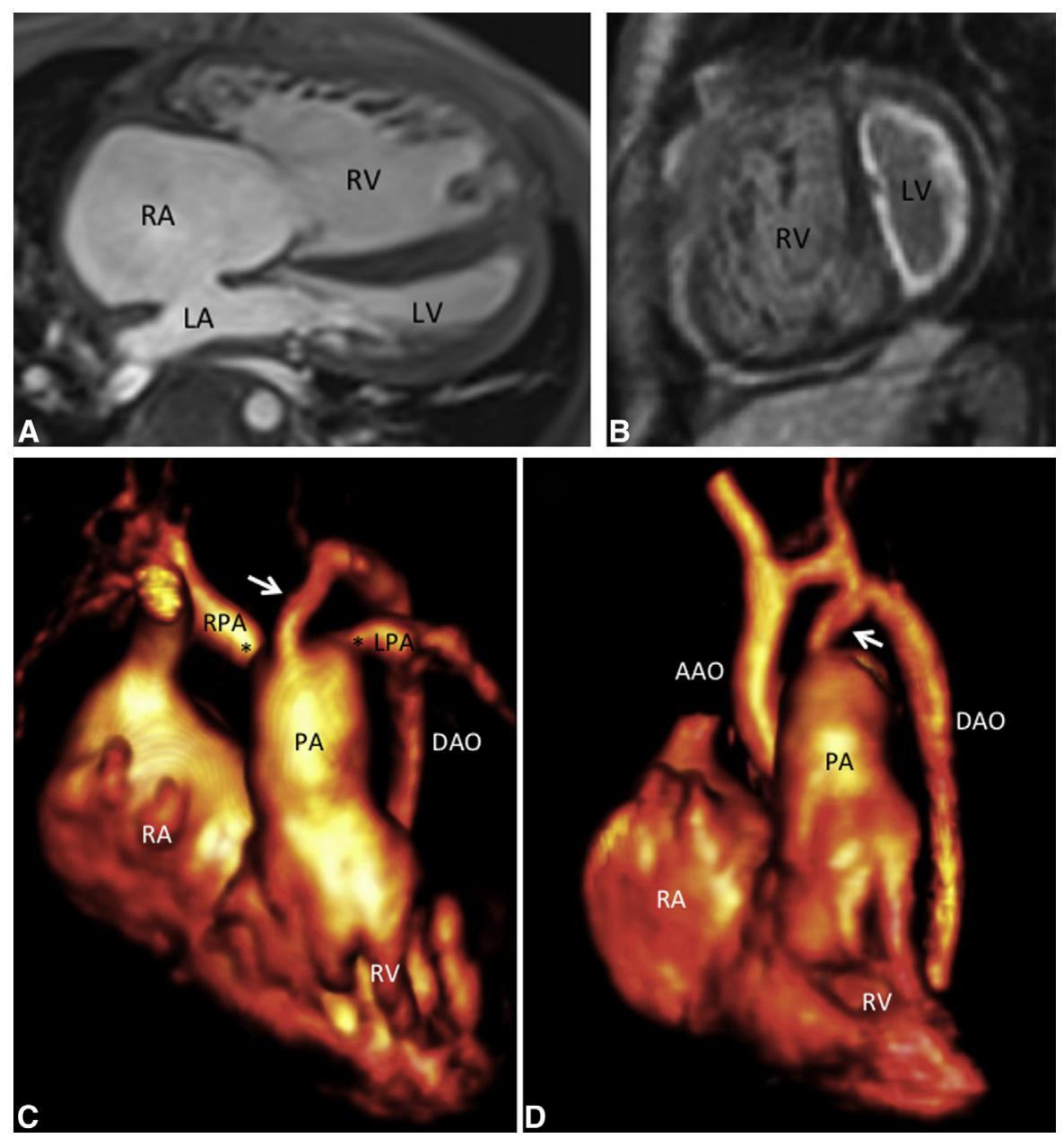

FIGURE 1. Cardiac magnetic resonance findings at 4 postoperative months. A, Four-chamber view showing the small left ventricle $(L V)$ and the dilated and hypertrophied right ventricle $(R V)$ with an enlarged right atrium $(R A)$ and an interatrial communication to the left atrium $(L A)$. B, Endocardial fibroelastosis of the left ventricle shown by contrast enhanced cardiovascular magnetic resonance (late gadolinium enhancement). $\mathrm{C}$, Three-dimensional surface-rendered reconstruction of a contrast-enhanced magnetic resonance angiogram in the early phase showing the dilated pulmonary artery trunk $(P A)$ with bilateral pulmonary arterial banding (asterisk), the descending aorta $(D A O)$, and the patent shunt from the pulmonary artery trunk to the descending aorta (arrow). D, In a later phase of the cardiovascular magnetic resonance angiogram, the small ascending aorta $(A A O)$ and the aortic arch are shown with the shunt (arrow) from the pulmonary artery trunk to the descending aorta. $R P A$, Right pulmonary artery; $L P A$, left pulmonary artery.

and echocardiography showed effective bPAB (pressure gradient of $55 \mathrm{~mm} \mathrm{Hg}$ ) and a predominant right-to-left shunt through the aortopulmonary shunt, resulting in transcutaneous saturations on his foot and hand of $82 \%$ to $85 \%$ and $93 \%$ to $96 \%$, respectively.

\section{DISCUSSION}

The critical decision of performing either a univentricular or biventricular circulation in patients with borderline LV structures in the neonatal period is challenging. Even with the help of predictive scores, which ought to calculate the success rate of either strategy, the long-term implications of an early decision remains unclear. Pursuing the pathway of biventricular repair in patients with a borderline LV may sometimes result in a failure of the 2-ventricle circulation. LV dysfunction can evolve and might be caused by systolic or diastolic ventricular impairment, which can be further aggravated by adverse RV-to-LV interaction when severe "out of proportion" PH occurs. ${ }^{2,3}$ In this situation, cardiac decompensation ensues, most frequently as a result of RV failure associated with a poor prognosis. Palliative therapies that allow acute decompression of the failing RV have been proposed in patients with a comparable pathophysiology $y^{3,4}$ and may provide valuable alternatives to combined heart-lung transplantation, which finally represents the only therapeutic option that is burdened by chronic shortage of donor organs. In the case presented here, the unique approach aimed to imitate cardiac physiology as in a "fetal parallel circulation." This procedure has been established by our group as the Giessen hybrid approach in neonates with borderline LV. ${ }^{1}$ The polytetrafluoroethylene tube between the pulmonary artery and 
the descending aorta allowed right-to-left shunting and prevented RV failure by relieving suprasystemic RV pressure to a systemic pressure level. The position of the distal shunt anastomosis distal to the subclavian artery would prevent a desaturation of the head vessels and upper extremity. This approach was combined with atrioseptectomy and bPAB to protect the pulmonary circulation from volume overload. Cardiopulmonary bypass was necessary for creation of the neo-ductus arteriosus for this patient in a critical hemodynamic situation. We therefore opted for a concomitant surgical atrial septectomy during the procedure. Furthermore, the result of a surgical atrioseptectomy under direct vision is in our view the most reliable route for a longer-term nonobstructive atrial septum.

At the same time that bPAB prevented active hypercirculation, atrioseptectomy avoided passive pulmonary flow obstruction. The measured pressure gradient of $55 \mathrm{~mm} \mathrm{Hg}$ across the bPAB highlights the fall in pulmonary vascular resistance. The increase in systemic blood flow, however, occurred at the expense of oxygen desaturation of the lower part of the body, as described in patients with idiopathic $\mathrm{PH}$ who were treated with a reversed Potts shunt. ${ }^{5}$
The aim of our rescue procedure was to prevent further episodes of cardiac decompensation caused by $\mathrm{PH}$ crises and leading to resuscitation. Whether the decline in the pulmonary vascular resistance would allow a successful heart transplant, or even a biventricular repair, however, remains unknown. Most probably, our strategy would allow a safer waiting time for a combined heart and lung transplant in future.

\section{References}

1. Akintürk H, Michel-Behnke I, Valeske K, Mueller M, Thul J, Bauer J, et al. Hybrid transcatheter-surgical palliation: basis for univentricular or biventricular repair: the Giessen experience. Pediatr Cardiol. 2007;28:79-87.

2. Gan CT, Lankhaar JW, Marcus JT, Westerhof N, Marques KM, Bronzwaer JG, et al. Impaired left ventricular filling due to right-to-left ventricular interaction in patients with pulmonary arterial hypertension. Am J Physiol Heart Circ Physiol. 2006;290:H1528-33.

3. Latus H, Apitz C, Schmidt D, Jux C, Mueller M, Bauer J, et al. Potts shunt and atrial septostomy in pulmonary hypertension caused by left ventricular disease. Ann Thorac Surg. 2013;96:317-9.

4. Latus H, Apitz C, Moysich A, Kerst G, Jux C, Bauer J, et al. Creation of a functional Potts shunt by stenting the persistent arterial duct in newborns and infants with suprasystemic pulmonary hypertension of various etiologies. J Heart Lung Transplant. 2014;33:542-6.

5. Blanc J, Vouhe P, Bonnet D. Potts shunt in patients with pulmonary hypertension. N Engl J Med. 2004;350:623.

\title{
Lessons learned from failed attempt at transcatheter closure of postoperative Gerbode defect
}

\author{
Syed T. Hussain, MD, ${ }^{\mathrm{a}}$ Kwabena Mawulawde, MD, ${ }^{\mathrm{a}}$ Samir R. Kapadia, MD, ${ }^{\mathrm{b}}$ \\ Eugene H. Blackstone, MD, ${ }^{\mathrm{a}, \mathrm{c}}$ and Gösta B. Pettersson, $\mathrm{MD}, \mathrm{PhD},{ }^{\mathrm{a}}$ Cleveland, Ohio
}

Video clip is available online.

The Gerbode defect, a direct communication between the left ventricle (LV) and right atrium (RA), is rare and may be either congenital or acquired. Acquired defects may be

\footnotetext{
From the Departments of Thoracic and Cardiovascular Surgery ${ }^{\mathrm{a}}$ and Cardiovascular Medicine, ${ }^{\mathrm{b}}$ Heart and Vascular Institute, and Department of Quantitative Health Sciences, ${ }^{\mathrm{c}}$ Research Institute, Cleveland Clinic, Cleveland, Ohio.

Disclosures: Authors have nothing to disclose with regard to commercial support.

Received for publication June 11, 2014; accepted for publication June 12, 2014; available ahead of print Aug 21, 2014.

Address for reprints: Gösta B. Pettersson, MD, PhD, Department of Thoracic and Cardiovascular Surgery, Cleveland Clinic, 9500 Euclid Ave, Desk J4-1, Cleveland, OH 44195 (E-mail: petterg@ ccf.org).

J Thorac Cardiovasc Surg 2014;148:e228-30

$0022-5223 / \$ 36.00$

Copyright (C) 2014 by The American Association for Thoracic Surgery

http://dx.doi.org/10.1016/j.jtcvs.2014.06.077
}

a result of complications of cardiac surgery, including aortic, mitral, or tricuspid valve repair or replacement, closure of a ventricular septal defect, endocarditis, or trauma. ${ }^{1}$ Surgical correction has been the treatment of choice, although a few case reports of transcatheter closure have recently been published. ${ }^{2}$ We report a case of surgical closure of an LV-RA shunt acquired after reoperative aortic and mitral valve surgery for remote infective endocarditis (IE), after a failed attempt to close the defect with the transcatheter approach.

\section{CLINICAL SUMMARY}

A 45-year-old man had undergone aortic valve (AV) replacement and mitral valve (MV) repair for IE in 2006. Recurrent IE in 2008 was treated with antibiotics. In 2013, he developed shortness of breath and was found to have degeneration of his AV bioprosthesis and heart failure. He underwent reoperation and had his aortic prosthesis 